\title{
The Mu-Opioid Receptor Polymorphism AI I8G Predicts Cortisol Responses to Naloxone and Stress
}

\author{
Rachel Y Chong', Lynn Oswald ${ }^{2}$, Xiaoju Yang', Magdalena Uhart', Ping-I Lin ${ }^{3}$ and Gary S Wand ${ }^{*, 1,2}$ \\ 'Department of Medicine, The Johns Hopkins University School of Medicine, Baltimore, MD, USA; '2Department of Psychiatry, The Johns Hopkins \\ University School of Medicine, Baltimore, MD, USA; ${ }^{3}$ Center for Human Genetics, Duke University Medical Center, Durham, NC, USA
}

\begin{abstract}
A polymorphism in the mu-opioid receptor (MOR) (AII8G) has been shown to increase $\beta$-endorphin binding affinity, theoretically placing greater inhibitory tone on hypothalamic corticotropin-releasing hormone $(\mathrm{CRH})$ neurons. We hypothesized that the minor allele (G) would predict cortisol responses to both pharmacological (naloxone) and psychological (stress) activation of the hypothalamicpituitary-adrenal (HPA) axis. Healthy subjects (mean age 25.2 years, SD 9.2 years) completed a naloxone challenge $(n=74)$ and/or the modified Trier Social Stress Test (TSST) $(n=86)$. For the naloxone challenge, two baseline blood samples were obtained. Then, five increasing doses of i.v. naloxone were administered at 30-min intervals and 12 additional blood samples were collected at 15 -min intervals. The TSST consisted of 5-min of public speaking and 5-min of mental arithmetic exercises. Three baseline and five post-TSST blood samples were drawn. Both the naloxone and TSST groups had significant adrenocorticotropin (ACTH) and cortisol responses to their respective challenges $(P<0.00 \mathrm{I})$. There were no differences in baseline $\mathrm{ACTH}$, baseline cortisol, or $\mathrm{ACTH}$ response by genotype in either the naloxone or the TSST group. Among subjects expressing a G allele, there was a higher cortisol response to naloxone $(P=0.046)$, but a lower cortisol response to the TSST $(P=0.044)$. In conclusion, the minor allele $(G)$ was associated with a robust cortisol response to naloxone blockade, but a blunted response to psychosocial stress. We speculate that increased opioid avidity of the minor allele receptor contributes to the differential response to naloxone vs stress.

Neuropsychopharmacology (2006) 31, 204-2II. doi:I0.1038/sj.npp. I 300856; published online 3 August 2005
\end{abstract}

Keywords: adrenocorticotropin; cortisol; naloxone; opioid receptor; polymorphism; stress

\section{INTRODUCTION}

Activation of the hypothalamic-pituitary-adrenal (HPA) axis is an important adaptive mechanism that enables the human body to return to homeostasis in response to physiological and psychosocial stressors. Cortisol, which is an end product of this activation, affects almost all physiological processes, including cardiovascular function, immune function, metabolism, cell growth, and HPA axis regulation. Chronic HPA axis dysregulation has been shown to contribute to a number of medical disorders including obesity, insulin resistance, hypertension, dyslipidemia, atherosclerosis, osteoporosis, and immune dysfunction (McEwen, 1998; Tsigos and Chrousos, 2002). It is also implicated in several psychoaffective

\footnotetext{
*Correspondence: Dr GS Wand, Departments of Medicine and Psychiatry, The Johns Hopkins University School of Medicine, Ross Research Building, Room 863, 720 Rutland Avenue, Baltimore, MD 2I205, USA, Tel: + I 410955 7225, Fax: + I 410955 084I,

E-mail: gwand@jhmi.edu

Received 28 March 2005; revised I 3 June 2005; accepted I 3 June 2005 Online publication: 30 June 2005 at http://www.acnp.org/citations/ Npp063005050206/default.pdf
}

disorders, including depression and alcoholism (Gianoulakis, 1998; Lee et al, 2002; Sapolsky, 2000).

The magnitude of HPA axis activation is regulated by the interaction of environmental and genetic determinants. Estimations of the heritability of cortisol responses to psychosocial stress range from approximately 33 to $97 \%$ (Federenko et al, 2004). Such moderate to high heritability has motivated a search for genes governing HPA axis dynamics. A candidate in this regard is the mu-opioid receptor (MOR) gene.

In recent years, investigators have identified numerous polymorphisms in the MOR gene. One such polymorphism of interest is the A118G single nucleotide polymorphism (SNP) in exon 1 of the MOR gene. This SNP results in an Asn40Asp substitution in the extracellular N-terminal domain of the MOR, and presumably the loss of a glycosylation site (Bergen et al, 1997; Bond et al, 1998; Mestek et al, 1995). An in vitro study demonstrated that the expression of the Asp40 allele causes a three-fold increase in binding affinity to $\beta$-endorphin and enhances G protein-coupled potassium channel activation. However, a subsequent study did not replicate these findings (Beyer et al, 2004; Bond et al, 1998). 
There have been several studies highlighting the pharmacogenetic significance of the A118G SNP. For instance, we previously showed that this polymorphism is associated with enhanced cortisol response to opioid blockade by naloxone (Wand et al, 2002). This finding was replicated by Hernandez-Avila et al (2003). Additionally, Lotsch et al (2002) demonstrated that the expression of the $G$ allele is associated with a decreased pupillary constriction to an opioid agonist. Also, Oslin et al (2003) showed that alcoholdependent persons carrying the $\mathrm{G}$ allele are more likely to respond to treatment with the opioid antagonist, naltrexone, than those homozygous for the A allele.

There is interest not only in investigating the pharmacogenetic significance of this polymorphism, but also in elucidating any influence it may have on neurobiological processes. One neurobiological process which may be modified by the A118G polymorphism is the HPA axis response to stress. Hypothalamic corticotropin-releasing hormone (CRH) neurons, which effect glucocorticoid release by stimulating pituitary adrenocorticotropin (ACTH) secretion, are directly and indirectly inhibited by $\beta$-endorphin-producing neurons via the MOR (Johnson et al, 1992). Both exaggerated and blunted HPA responses to stress have been associated with certain affective illnesses (Bremner et al, 2003; Heim et al, 2001; Peeters et al, 2003). What is more, studies have suggested that opioids play an important role in response to stress, motivation, and numerous psychiatric entities such as depression, anxiety, and substance dependence (Djurovic et al, 1999; Drolet et al, 2001; Kieffer and Gaveriaux-Ruff, 2002; King et al, 2002; Kreek and Koob, 1998; Vaccarino and Kastin, 2000; Van Ree et al, 2000). Also, the minor allele of the A118G MOR polymorphism has a frequency as high as 0.489 within racial groups (rs1799971 (http://www.hapmap.org/)), so the potential functionality of this SNP is of particular interest.

The purpose of the present study was two-fold. First, we aimed to replicate our original finding (Wand et al, 2002) with a larger sample size. Therefore, we investigated whether the A118G MOR polymorphism predicted cortisol responses to activation by naloxone. Second, given the pathophysiological significance of aberrant cortisol exposure and how it is influenced by genetics, we were also motivated to seek a potential contribution of the A118G SNP to the glucocorticoid response to stress. We hypothesized the A118G MOR polymorphism would also predict cortisol response to psychological stress. To this end, we administered a standardized psychosocial stress test to healthy male and female subjects and measured their ACTH and cortisol responses.

\section{MATERIALS AND METHODS}

\section{Recruitment}

Our study was conducted between the years 2000 and 2004 . Healthy males and females from the Baltimore area between the ages of 18 and 65 years were recruited by newspaper advertisements. After being screened by a telephone interview, eligible individuals were invited for an interview at the study center. For each subject, written informed consent was obtained for the protocol, which had been approved by the Johns Hopkins University School of Medicine Institu- tional Review Board. A physician obtained a medical history and physical exam. A complete blood count, comprehensive metabolic panel (including renal and hepatic function tests), electrocardiogram, urinalysis, alcohol breathalyzer test, and urine toxicology screen were obtained for exclusion criteria. A urine pregnancy test was obtained on each female subject. The Semi-Structured Assessment for the Genetics of Alcoholism (SSAGA) (Bucholz et al, 1994) was administered by a master's degree-level interviewer to identify DSM-IV axis I psychiatric diagnoses. The Fagerstrom test was used to determine nicotine dependence (Richardson and Ratner, 2005).

Exclusion criteria were as follows: presence of a serious medical condition; presence of a DSM-IV axis I disorder (including alcohol or drug dependence); nicotine dependence; use of any psychoactive medications within the past 30 days; treatment in the last 6 months with any medication that may affect opioid or HPA axis function, including antidepressants, neuroleptics, sedative hypnotics, glucocorticoids, appetite suppressants, estrogens, opiates, or dopamine medications; presence of a seizure disorder; history of closed head trauma; consumption of more than 30 alcoholic drinks per month; positive urine toxicology screen; or, for females, pregnancy or lack of an effective nonhormonal method of birth control.

All females were premenopausal and were required to keep menstrual diaries. Females were studied during the follicular phase, which was defined as the first 12 days of the menstrual cycle counting from the first day of menstrual bleeding.

A total of 86 subjects participated in the modified Trier Social Stress Test (TSST) and 74 subjects participated in the naloxone challenge portion of the study. Of these subjects, 43 underwent both the naloxone challenge and the TSST. Thus, there were 117 subjects in all.

\section{General Procedure}

After completing the initial assessment interview, subjects reported to the Johns Hopkins Hospital Outpatient General Clinical Research Area to complete the naloxone challenge and/or the TSST. For the subset of subjects who were to undergo both challenges, one challenge was completed on 1 day, and the other challenge on a separate day within a week. The order in which the challenges were completed was randomized. Subjects were instructed to record any stressful events in the week before and to sleep adequately the night prior to participating in the challenges. They were also requested to refrain from any alcohol, illicit drugs, or over-the-counter medications for $48 \mathrm{~h}$ prior to participating in the study protocol. Urine toxicology screens were completed before each session. On the day of each challenge, subjects fasted from 1000 hours until testing was completed. All procedures were performed under the same conditions for each subject, with the same study personnel and in the same study room.

\section{Naloxone Challenge}

For the naloxone challenge, subjects received five doses of naloxone according to the one day, single-session protocol reported by Mangold et al (2000). At 1200 hours, an 
intravenous catheter was placed in a forearm vein. After $45 \mathrm{~min}$ (time $-15 \mathrm{~min}$ ) and $60 \mathrm{~min}$ later, blood was drawn to establish baseline ACTH and cortisol concentrations. A bolus of $0.9 \%$ saline was then immediately administered as a placebo; this was designated as time $0 \mathrm{~min}$. Naloxone dissolved in $0.9 \%$ saline was administered at $30,60,90$, and $120 \mathrm{~min}$. In all, a total of five increasing doses of naloxone were administered $(0,50,100,200$, and $400 \mu \mathrm{g} / \mathrm{kg})$. Blood was drawn at $15,30,45,60,75,90,105,120,135,150,165$, and $180 \mathrm{~min}$.

\section{Trier Social Stress Test}

The TSST was completed as previously described (Uhart et al, 2004). This protocol was based on the original protocol by Kirschbaum et al (1993). An intravenous catheter was placed at 1200 hours and 1 hour later three blood samples were drawn at 15-min intervals to establish baseline ACTH and cortisol concentrations. Subjects listened to audiotaped instructions for $5 \mathrm{~min}$, then given 10 min to mentally prepare for their performance task, then $5 \mathrm{~min}$ to complete a public speaking task, and finally $5 \mathrm{~min}$ to complete a mental arithmetic task. Immediately following completion of these tasks, five more blood samples for ACTH and cortisol were obtained at 15-min intervals.

\section{Hormone Assays}

Plasma ACTH concentration was measured by the Nichols immunoradiometric assay. Intra-assay and inter-assay coefficients of variance were each less than 9\%. Plasma cortisol concentration was assayed by radioimmunoassay (Diagnostic Products Corporation, Inc., Los Angeles, CA). Intra-assay and inter-assay coefficients of variance were 6 and $8.5 \%$, respectively.

\section{Determination of Genotypes}

Genomic leukocyte DNA was extracted from whole blood by the Puregene DNA isolation method (Gentra Systems Inc.). For 32 of the 117 subjects, genotyping was performed using PCR followed by denaturing gradient gel electrophoresis according to our previously described protocol (Wand et al, 2002). For the remaining 85 subjects, genotyping was performed by fluorescent melting curve analysis using a LightCycler (Roche Diagnostics). Primers and probes were obtained from Roche. Sequences from exon 1 of the human MOR gene were used to design PCR primers and hybridization probes for the amplification of a portion of DNA containing the A118G polymorphism. The forward primer used was $5^{\prime}$-GATGCCTTGGCGTACTC-3', and the reverse primer used was $5^{\prime}$-ATGGCCGTGATCATGGA-3'. The sensor probe was $5^{\prime}$-CGGACCGCATGGGTCGG-3'fluoroscein. The anchor probe was LightCyclerRed $640-5^{\prime}-$ AGGTCGCCATCTAAGTGGGACAA-3'-phosphate. The reactions were performed in a total volume of $20.0 \mu \mathrm{l}$ in LightCycler glass capillaries. The reaction mixture consisted of $11.4 \mu \mathrm{l}$ of distilled water, $1.6 \mu \mathrm{l}$ of $\mathrm{MgCl}_{2}(25 \mathrm{mM}), 1.0 \mu \mathrm{l}$ of each primer $(10 \mu \mathrm{M}), 1.0 \mu \mathrm{l}$ of the sensor probe $(4 \mu \mathrm{M})$, $1.0 \mu \mathrm{l}$ of the anchor probe $(8 \mu \mathrm{M}), 2.0 \mu \mathrm{l}$ of LightCycler DNA-Master Hybridization Probes (Roche Diagnostics), and $1.0 \mu \mathrm{l}$ of genomic DNA (100-500 ng). PCR conditions were as follows: denaturation at $95^{\circ} \mathrm{C}$ for $10 \mathrm{~min}$, followed by 45 cycles of denaturation at $95^{\circ} \mathrm{C}$ for $10 \mathrm{~s}$, annealing at $60^{\circ} \mathrm{C}$ for $10 \mathrm{~s}$, and extension at $72^{\circ} \mathrm{C}$ for $10 \mathrm{~s}$.

Following amplification, melting curve analysis was performed with denaturation at $95^{\circ} \mathrm{C}$ for $15 \mathrm{~s}$, annealing at $50^{\circ} \mathrm{C}$ for $30 \mathrm{~s}$, and increasing the temperature to $80^{\circ} \mathrm{C}$ at a rate of $0.3^{\circ} \mathrm{C} / \mathrm{s}$. Cooling was performed at $40^{\circ} \mathrm{C}$ for $30 \mathrm{~s}$. The fluorescence emitted was measured and the melting curve $(F / T)$ was converted to melting peaks $(-\mathrm{d} F / \mathrm{d} T)$ by LightCycler software.

\section{Statistical Analysis}

Preliminary analyses included evaluation of genotype group differences (AA vs AG and GG) in demographic characteristics with $t$-tests for continuous variables (age, body mass index (BMI), and level of education) and $\chi^{2}$ analyses for categorical variables (gender, race, and smoking status). The major outcomes of interest were ACTH and cortisol concentrations following the naloxone challenge and the TSST. ACTH and cortisol measurements were transformed to the logarithmic scale because of non-normality. The mean baseline for each hormone was calculated by taking the average of the baseline measurements $(-30,-15$, and 0 min time point for the TSST measurements and -15 and 0 min time point for the naloxone challenge measurements). The mean baseline differences in ACTH and cortisol concentration between genotype groups were also analyzed by $t$-tests.

We then carried out three different types of analyses to assess the effect of genotype on ACTH and cortisol responses in each of the two challenge groups. For each analysis, we incorporated gender, age, race, BMI, and level of education in the model to adjust for demographic differences in both the naloxone challenge and TSST groups. Level of education was used as a proxy of socioeconomic status. We controlled for socioeconomic status because of its relationship with stress-related hormones (Kunz-Ebrecht et al, 2004; Steptoe et al, 2003). BMI was added because a pharmacologic agent was administered. Baseline hormone values were also added to each model because baseline hormone values were consistently highly correlated with maximum hormone responses (ACTH in naloxone challenge group: $r=0.61$, $P<0.001$; cortisol in naloxone challenge group: $r=0.62$, $P<0.001$; ACTH in TSST group: $r=0.71, P$-value $<0.001$; cortisol in TSST group: $r=0.56, P$-value $<0.001)$.

First, we performed longitudinal data analysis. Each hormone measurement at each time point was treated as the outcome in the generalized linear model using generalized estimating equations (GEE) to take into account the within-individual correlation residuals arising from repeated measurements for each individual (Zeger and Liang, 1986). The model included genotypic effect on hormonal measurements as the major covariate of interest, time, and time $^{2}$ to adjust for nonlinear time trend. Second, we conducted post-hoc regression analyses to evaluate the genotypic effect on differences in hormone response at each time point. Third, we carried out area under the curve (AUC) analyses. ACTH and cortisol AUC values for two genotype groups were computed by using the trapezoid algorithm, and the effect of genotype on differences in the 
AUC were assessed by using the generalized linear model. The analyses were two-sided with a 0.05 significance level and were performed by using the software, STATA 8.0. Finally, we plotted the adjusted means of ACTH and cortisol concentrations to the two challenges against time by genotype. The adjusted mean values were calculated based on estimated mean values of all covariates in the models.

\section{RESULTS}

Demographic and genotypic information for the subjects undergoing the naloxone challenge $(n=74)$, and modified TSST $(n=86)$ are in Table 1 . There was only one subject in the study with the GG genotype. This subject underwent the naloxone challenge and was grouped with the subjects with the AG polymorphism for subsequent statistical analyses. There were no statistically significant differences between genotypes in terms of sex, race, smoking status, age, BMI, or level of education.

\section{Naloxone Challenge}

By longitudinal analysis using GEE, the naloxone challenge subjects as a group had significant ACTH and cortisol responses to naloxone $(P<0.001$ for each). ACTH and cortisol concentrations did not differ at baseline or following placebo by genotype. Compared to those homozygous for the A allele, subjects with the $G$ allele had no significant difference in ACTH response, but did have a significantly greater cortisol response $(P=0.046)$ to nalox- one (Figure 1a and b). Similarly, ACTH response by AUC analysis was not different by genotype, but subjects carrying the $G$ allele had a significantly greater AUC cortisol response $(P=0.041)$.

\section{Modified TSST}

By longitudinal analysis using GEE, the TSST subjects as a group had significant ACTH and cortisol responses to the TSST ( $P<0.001$ for each). ACTH and cortisol concentrations did not differ at baseline by genotype. Compared to those homozygous for the A allele, subjects with the $G$ allele had no significant difference in ACTH response, but did have a significantly lower cortisol response $(P=0.044)$ to the TSST (Figure 2a and $\mathrm{b}$ ). ACTH response did not differ between genotype groups by AUC analysis. The AUC cortisol response of the G-allele group was less than that of the group homozygous for the A-allele with marginal statistical significance $(P=0.058)$.

\section{DISCUSSION}

The present study demonstrated that individuals expressing the minor allele $(\mathrm{G})$ of the A118G MOR polymorphism had an exaggerated cortisol response to naloxone compared to subjects expressing only the major allele. Thus, in this study, we reproduced our earlier results (Wand et al, 2002). Furthermore, we observed that subjects expressing the $G$ allele of the SNP had a blunted cortisol response to psychosocial stress. Our results suggest that the A118G

Table I Demographics According to MOR AII8G Polymorphism of the Naloxone Challenge Group and TSST Group

\begin{tabular}{|c|c|c|c|c|c|}
\hline & \multirow[b]{2}{*}{ AA } & \multicolumn{2}{|c|}{ Naloxone challenge $n=74^{\mathrm{a}}$} & \multicolumn{2}{|c|}{ TSST $n=86^{a}$} \\
\hline & & AG & GG & AA & AG \\
\hline \multicolumn{6}{|l|}{ Gender, No. (\%) } \\
\hline \multicolumn{6}{|l|}{ Race, No. (\%) } \\
\hline Caucasian & $47(80)$ & $10(7 \mid)$ & I $(100)$ & $42(70)$ & $18(69)$ \\
\hline African-American & $9(15)$ & $2(14)$ & 0 & $15(25)$ & $5(19)$ \\
\hline Asian & $3(5)$ & $2(14)$ & 0 & $3(5)$ & $3(12)$ \\
\hline \multicolumn{6}{|l|}{ Smoking status, No. (\%) } \\
\hline Nonsmoker & $58(98)$ & $14(100)$ & I $(100)$ & $58(97)$ & $23(88)$ \\
\hline Age, mean (SD) (years) & $21.0(2.0)$ & $22.4(3.8)$ & $19.0(-)$ & $26.0(10.2)$ & $27.7(10.8)$ \\
\hline $\mathrm{BMI}$, mean $(\mathrm{SD})\left(\mathrm{kg} / \mathrm{m}^{2}\right)$ & $24.5(3.0)$ & $24.9(3.6)$ & $20.6(-)$ & $25.5(4.1)$ & $24.2(3.7)$ \\
\hline Education, mean (SD) (years) & |4.2(I.5) & | $4.4(2.0)$ & $14.0(-)$ & | $4.5(1.8)$ & | $4.7(1.8)$ \\
\hline
\end{tabular}

an all, 43 subjects in the naloxone challenge group also belonged to the TSST group. Thus, 3 I subjects belonged only to the naloxone challenge group, and 43 belonged only to the TSST group. There were a total of I I 7 subjects in all.

${ }^{b}$ Smokers smoked equal to or less than 10 cigarettes per day and did not meet criteria for tobacco dependence. 

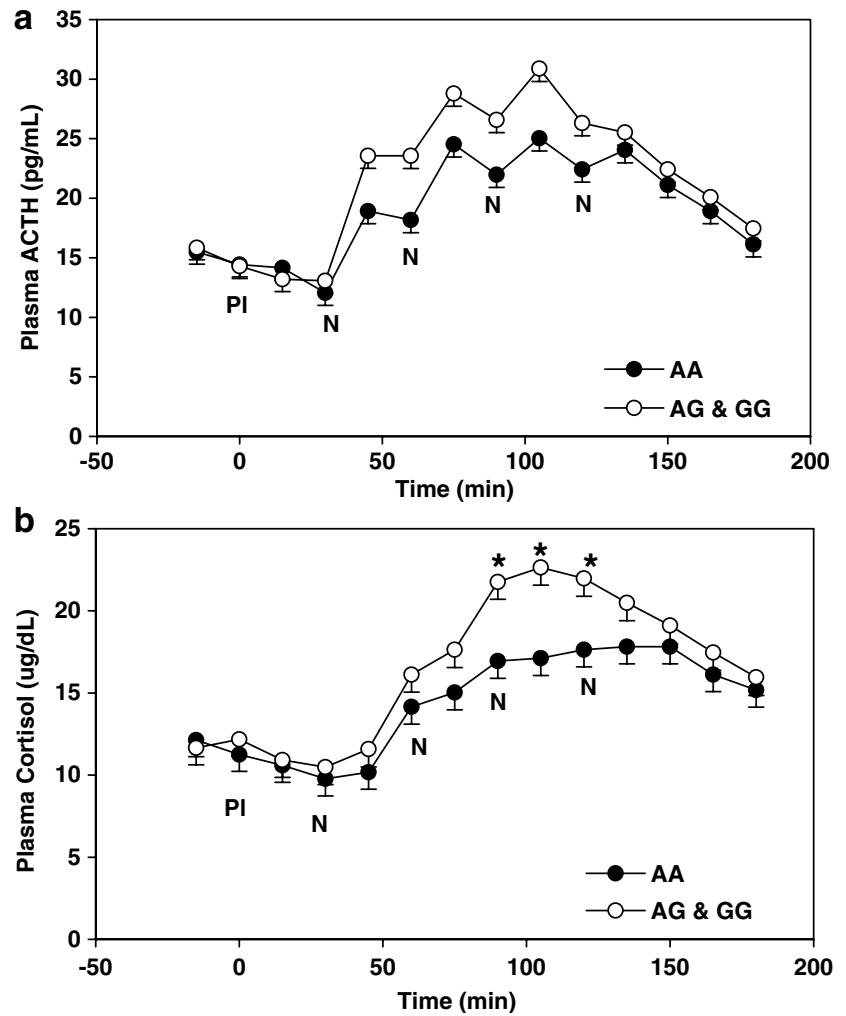

Figure I (a) Plasma ACTH response to naloxone by genotype. Values reflect means (SE) adjusted for gender, age, race, BMI, level of education, and baseline ACTH. PI denotes time of placebo (saline) administration. N denotes times of incremental naloxone administration. (b) Plasma cortisol response to naloxone by genotype. Values reflect means (SE) adjusted for gender, age, race, BMI, level of education, and baseline cortisol. PI denotes time of placebo (saline) administration. $\mathrm{N}$ denotes times of incremental naloxone administration. * denotes time points at which cortisol differed significantly between genotypes. Plasma cortisol concentration differed by genotype at the following time points: $90 \mathrm{~min}, P=0.001$; $105 \mathrm{~min}$, $P=0.002$; and $120 \mathrm{~min}, P=0.042$ by post hoc analysis following longitudinal analysis by GEE.

MOR SNP exerts not only a pharmacogenetic effect on naloxone-induced activation of the HPA axis, but also an effect on HPA axis activation by stress. However, the genotype effect on TSST cortisol responses was modest and requires replication.

To our knowledge, this study is the largest one to date examining the relationship between the A118G MOR SNP and glucocorticoid response to naloxone. Hernandez-Avila et al (2003) reported a similar association between cortisol response to naloxone and the G allele of this SNP in 30 healthy subjects . Prior to these findings, it had been shown that higher cortisol responses to naloxone are more likely in those with a family history of alcoholism (Hernandez-Avila et al, 2002; Wand et al, 2001). Given that altered cortisol responses to stress are observed in patients at risk for affective illness and alcoholism and in those suffering from substance abuse disorders (Dai et al, 2002; Modell et al, 1998; Wand et al, 2001), it is interesting that there is evidence (albeit conflicting) for the association between the A118G MOR SNP and alcohol and opioid dependence. Several human studies have suggested that the 118A allele
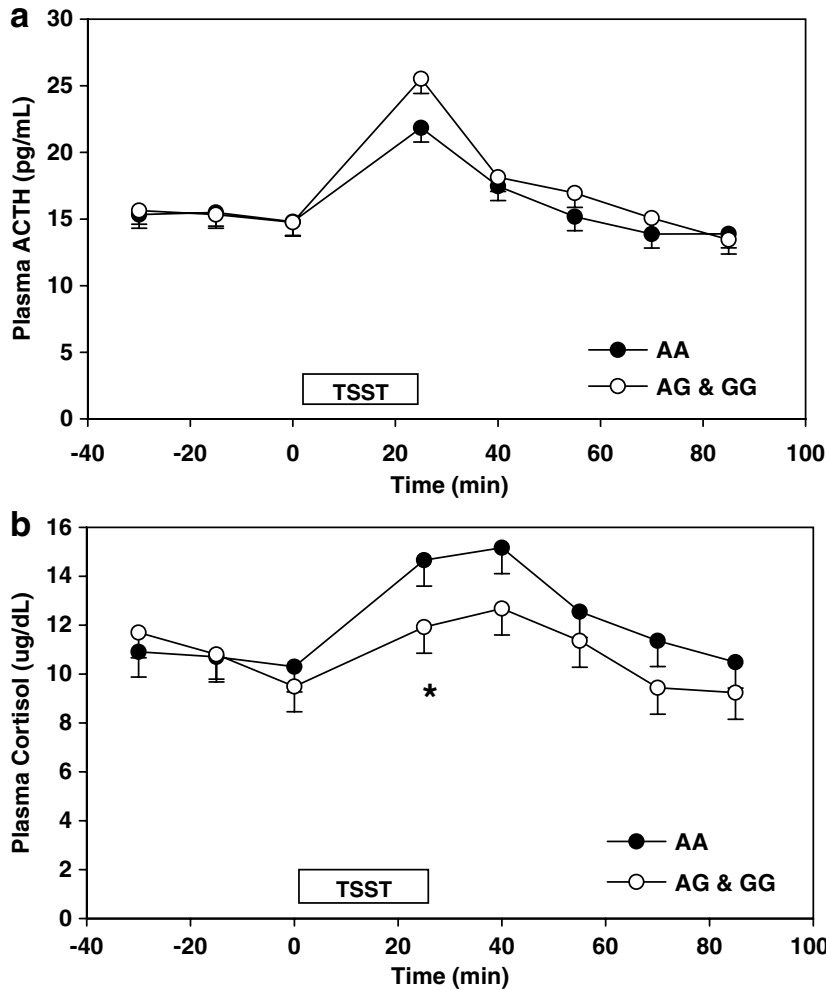

Figure 2 (a) Plasma ACTH response to TSST by genotype. Values reflect means (SE) adjusted for gender, age, race, BMI, level of education, and baseline ACTH. (b) Plasma cortisol response to TSST by genotype. Values reflect means (SE) adjusted for gender, age, race, BMI, level of education, and baseline cortisol. * denotes the time point at which cortisol differed significantly between genotypes. Plasma cortisol concentration differed by genotype at time $25 \mathrm{~min}, P=0.016$ by post hoc analysis following longitudinal analysis by GEE.

may be a risk factor for opiate and other drug addiction. (Bond et al, 1998; Schinka et al, 2002; Tan et al, 2003; Town et al, 1999). Conversely, it has been reported that the $118 \mathrm{G}$ allele is more common in opioid-dependent (Szeto et al, 2001) and alcohol-dependent (Bart et al, 2005) individuals, and is associated with heavier drinking (Kim et al, 2004). A recent study demonstrated that this minor allele was linked to more robust subjective responses to alcohol and a positive family history of alcohol use disorders among healthy subjects (Ray and Hutchison, 2004). Still, other studies have found no association between this polymorphism and substance dependence (Bergen et al, 1997; Compton et al, 2003; Crowley et al, 2003; Franke et al, 2001; Gelernter et al, 1999; Hoehe et al, 2000; Ide et al, 2004; Loh et al, 2004; Luo et al, 2003; Sander et al, 1998; Shi et al, 2002). Also, Luo et al (2003) found that while haplotypes at the OPRM1 locus are associated with substance abuse, the A118G polymorphism did not contribute any further information.

While there is evidence for the pharmacological significance of the A118G MOR polymorphism, its physiological impact on the HPA axis stress response has been unclear. Our findings, as far as we know, are the first to demonstrate that the $G$ allele of the A118G MOR polymorphism is associated with a blunted HPA response to psychosocial stress in humans. Even a small difference in cortisol 
responses to psychological stress by genotype could result in substantial divergence in lifetime cortisol exposure and allostatic load (McEwen, 1998). Our results are consistent with a recent study in the non-human primate literature by Miller et al (2004). They found that the minor allele of the C77G MOR polymorphism in the rhesus monkey is associated with lower basal and ACTH-stimulated cortisol levels, and higher aggression. Similar to the A118G SNP in the human MOR, this SNP results in an amino-acid exchange in the N-terminus of the rhesus monkey MOR and confers a greater affinity for $\beta$-endorphin.

Why might the A118G MOR polymorphism confer an exaggerated cortisol response to opioid receptor blockade with naloxone, but a dampened response to psychosocial stress? The hypothalamic $\mathrm{CRH}$ neurons receive direct inhibitory input from $\beta$-endorphin-producing neurons located in the arcuate nucleus. In addition, $\beta$-endorphinproducing neurons inhibit norepinephrine neurons, which provide direct stimulatory input to hypothalamic $\mathrm{CRH}$ neurons (Jackson et al, 1990). One could posit that compared with individuals expressing only the A allele, persons expressing the $G$ allele (and hence a higher-affinity MOR) have higher inhibitory opioidergic tone directed at $\mathrm{CRH}$ neurons. Therefore, upon naloxone blockade, they experience a more dramatic rebound in cortisol levels. However, a receptor with enhanced binding affinity for $\beta$ endorphin results in a different hormonal pattern when the HPA axis is activated by psychological stress. Specifically, the more opioid-avid MOR ( $G$ allele) places increased inhibitory tone on $\mathrm{CRH}$ neurons, thus dampening cortisol responses to psychological stress.

Seeming to contradict this proposed hypothalamic mechanism is the observation that differences between genotypes in both the naloxone challenge and TSST groups were observed in only the cortisol response, and not the $\mathrm{ACTH}$ response. It may have been that our study was underpowered to detect a significant difference in ACTH response by genotype. On the other hand, one could speculate that the $\mathrm{G}$ allele induces a gradual increase in HPA axis activity. This change would begin at the hypothalamus and ultimately be reflected at the adrenocortical level in increased cortisol concentrations. This alteration in HPA axis dynamics, however, may not be obvious at the hypothalamic-pituitary level as a result of negative feedback by cortisol on ACTH release. Alternatively, the lack of a genotype effect on ACTH response in the naloxone challenge could be explained by a direct action of naloxone on adrenal gland opioid receptors. Such an action could affect cortisol production or release independent of ACTH. Indeed, one study demonstrated that opioid peptides stimulate corticosterone secretion by inner zone cells of the rat adrenal cortex in vitro, and that this effect is blocked by naloxone (Kapas et al, 1995). We should also be clear that our findings, regardless of where it is affecting HPA axis function, may not be the result of the A118G SNP itself. Instead, this proposed functional polymorphism, which exists as part of a $55 \mathrm{~kb}$ haplotype block, may be merely a marker for a haplotype which influences MOR function or expression (http://www.broad.mit.edu/mpg/haploview/).

There are several weaknesses to our study. For one, it would have been ideal to have a larger sample size and then analyze only subjects who completed both the naloxone challenge and the TSST, thereby reducing hormone variability. In a within-subject design, hormone differences between genotypes most likely would have been even more dramatic. It is also conceivable that the timing of cortisol measurements following the TSST may have missed peak responses, and that a greater genotypic effect could have been observed had we chosen a different set of time points to collect poststress hormone samples. Furthermore, population stratification (ie, differences in allele frequencies between groups arising from systematic differences in ancestry instead of association of genes) could have confounded our results. Adjusting for demographic characteristics in our statistical models likely mitigated bias induced by any population stratification. Nevertheless, we could not control for gene-based population stratification by using, for instance, genomic controls. Additionally, it may have been desirable to control for other factors affecting HPA axis response in our analysis, such as early adverse events and personality. Finally, our findings are based on laboratory-based settings rather than real-life situations. It is important to know whether the $G$ allele would predict cortisol responses to other types of stressors.

In conclusion, the $118 \mathrm{G}$ MOR gene allele is associated with a robust HPA axis response to naloxone blockade, but a blunted response to psychosocial stress. Further laboratory studies are needed to assess the specific neurotransmitter and hormonal pathways responsible for these phenomena.

\section{ACKNOWLEDGEMENTS}

This work was supported by NIH Grants AA10158 and AA12303 (GSW); and in part by NIH Grant K12 RR01762701 (RYC). We thank Dr Deborah Ann McClellan for her help in editing this manuscript.

\section{REFERENCES}

Bart G, Kreek MJ, Ott J, LaForge KS, Proudnikov D, Pollak L et al (2005). Increased attributable risk related to a functional muopioid receptor gene polymorphism in association with alcohol dependence in Central Sweden. Neuropsychopharmacology 30: 417-422.

Bergen AW, Kokoszka J, Peterson R, Long JC, Virkkunen M, Linnoila $\mathrm{M}$ et al (1997). Mu opioid receptor gene variants: lack of association with alcohol dependence. Mol Psychiatr 2: 490-494.

Beyer A, Koch T, Schroder H, Schulz S, Hollt V (2004). Effect of the A118G polymorphism on binding affinity, potency and agonistmediated endocytosis, desensitization, and resensitization of the human mu-opioid receptor. J Neurochem 89: 553-560.

Bond C, LaForge KS, Tian M, Melia D, Zhang S, Borg L et al (1998). Single-nucleotide polymorphism in the human mu opioid receptor gene alters beta-endorphin binding and activity: possible implications for opiate addiction. Proc Natl Acad Sci USA 95: 9608-9613.

Bremner JD, Vythilingam M, Vermetten E, Adil J, Khan S, Nazeer A et al (2003). Cortisol response to a cognitive stress challenge in posttraumatic stress disorder (PTSD) related to childhood abuse. Psychoneuroendocrinology 28: 733-750.

Bucholz KK, Cadoret R, Cloninger CR, Dinwiddie SH, Hesselbrock VM, Nurnberger Jr JI et al (1994). A new, semi-structured psychiatric interview for use in genetic linkage studies: a report on the reliability of the SSAGA. J Stud Alcohol 55: 149-158. 
Compton P, Geschwind DH, Alarcon M (2003). Association between human mu-opioid receptor gene polymorphism, pain tolerance, and opioid addiction. Am J Med Genet B Neuropsychiatr Genet 121: 76-82.

Crowley JJ, Oslin DW, Patkar AA, Gottheil E, Demaria Jr PA, O'brien CP et al (2003). A genetic association study of the mu opioid receptor and severe opioid dependence. Psychiatr Genet 13: $169-173$.

Dai X, Thavundayil J, Gianoulakis C (2002). Response of the hypothalamic-pituitary-adrenal axis to stress in the absence and presence of ethanol in subjects at high and low risk of alcoholism. Neuropsychopharmacology 27: 442-452.

Djurovic D, Milic-Askrabic J, Majkic-Singh N (1999). Serum betaendorphin level in patients with depression on fluvoxamine. Farmaco 54: 130-133.

Drolet G, Dumont EC, Gosselin I, Kinkead R, Laforest S, Trottier JF (2001). Role of endogenous opioid system in the regulation of the stress response. Prog Neuropsychopharmacol Biol Psychiatr 25: 729-741.

Federenko IS, Nagamine M, Hellhammer DH, Wadhwa PD, Wust S (2004). The heritability of hypothalamus pituitary adrenal axis responses to psychosocial stress is context dependent. J Clin Endocrinol Metab 89: 6244-6250.

Franke P, Wang T, Nothen MM, Knapp M, Neidt H, Albrecht S et al (2001). Nonreplication of association between mu-opioid-receptor gene (OPRM1) A118G polymorphism and substance dependence. Am J Med Genet 105: 114-119.

Gelernter J, Kranzler H, Cubells J (1999). Genetics of two mu opioid receptor gene (OPRM1) exon I polymorphisms: population studies, and allele frequencies in alcohol- and drugdependent subjects. Mol Psychiatry 4: 476-483.

Gianoulakis C (1998). Alcohol-seeking behavior: the roles of the hypothalamic-pituitary-adrenal axis and the endogenous opioid system. Alcohol Health Res World 22: 202-210.

Heim C, Newport DJ, Bonsall R, Miller AH, Nemeroff CB (2001). Altered pituitary-adrenal axis responses to provocative challenge tests in adult survivors of childhood abuse. Am J Psychiatr 158: 575-581.

Hernandez-Avila CA, Oncken C, Van KJ, Wand G, Kranzler HR (2002). Adrenocorticotropin and cortisol responses to a naloxone challenge and risk of alcoholism. Biol Psychiatr 51: 652-658.

Hernandez-Avila CA, Wand G, Luo X, Gelernter J, Kranzler HR (2003). Association between the cortisol response to opioid blockade and the Asn40Asp polymorphism at the mu-opioid receptor locus (OPRM1). Am J Med Genet B Neuropsychiatr Genet 118: 60-65.

Hoehe MR, Kopke K, Wendel B, Rohde K, Flachmeier C, Kidd KK et al (2000). Sequence variability and candidate gene analysis in complex disease: association of $\mathrm{mu}$ opioid receptor gene variation with substance dependence. Hum Mol Genet 9 : 2895-2908.

Ide S, Kobayashi $\mathrm{H}$, Tanaka K, Ujike $\mathrm{H}$, Sekine $\mathrm{Y}$, Ozaki $\mathrm{N}$ et al (2004). Gene polymorphisms of the mu opioid receptor in methamphetamine abusers. Ann NY Acad Sci 1025: 316-324.

Jackson RV, Grice JE, Jackson AJ, Hockings GI (1990). Naloxoneinduced ACTH release in man is inhibited by clonidine. Clin Exp Pharmacol Physiol 17: 179-184.

Johnson EO, Kamilaris TC, Chrousos GP, Gold PW (1992). Mechanisms of stress: a dynamic overview of hormonal and behavioral homeostasis. Neurosci Biobehav Rev 16: 115-130.

Kapas S, Purbrick A, Hinson JP (1995). Action of opioid peptides on the rat adrenal cortex: stimulation of steroid secretion through a specific mu opioid receptor. J Endocrinol 144: $503-510$.

Kieffer BL, Gaveriaux-Ruff C (2002). Exploring the opioid system by gene knockout. Prog Neurobiol 66: 285-306.
Kim SG, Kim CM, Kang DH, Kim YJ, Byun WT, Kim SY et al (2004). Association of functional opioid receptor genotypes with alcohol dependence in Koreans. Alcohol Clin Exp Res 28: 986-990.

King AC, Schluger J, Gunduz M, Borg L, Perret G, Ho A et al (2002). Hypothalamic-pituitary-adrenocortical (HPA) axis response and biotransformation of oral naltrexone: preliminary examination of relationship to family history of alcoholism. Neuropsychopharmacology 26: 778-788.

Kirschbaum C, Pirke KM, Hellhammer DH (1993). The 'Trier Social Stress Test' - a tool for investigating psychobiological stress responses in a laboratory setting. Neuropsychobiology 28: 76-81.

Kreek MJ, Koob GF (1998). Drug dependence: stress and dysregulation of brain reward pathways. Drug Alcohol Depend 51: 23-47.

Kunz-Ebrecht SR, Kirschbaum C, Steptoe A (2004). Work stress, socioeconomic status and neuroendocrine activation over the working day. Soc Sci Med 58: 1523-1530.

Lee AL, Ogle WO, Sapolsky RM (2002). Stress and depression: possible links to neuron death in the hippocampus. Bipolar Disord 4: 117-128.

Loh EW, Fann CS, Chang YT, Chang CJ, Cheng AT (2004). Endogenous opioid receptor genes and alcohol dependence among Taiwanese Han. Alcohol Clin Exp Res 28: 15-19.

Lotsch J, Skarke C, Grosch S, Darimont J, Schmidt H, Geisslinger G (2002). The polymorphism A118G of the human mu-opioid receptor gene decreases the pupil constrictory effect of morphine-6-glucuronide but not that of morphine. Pharmacogenetics 12: 3-9.

Luo X, Kranzler HR, Zhao H, Gelernter J (2003). Haplotypes at the OPRM1 locus are associated with susceptibility to substance dependence in European-Americans. Am J Med Genet B Neuropsychiatr Genet 120: 97-108.

Mangold D, McCaul ME, Ali M, Wand GS (2000). Plasma adrenocorticotropin responses to opioid blockade with naloxone: generating a dose-response curve in a single session. Biol Psychiatr 48: 310-314.

McEwen BS (1998). Protective and damaging effects of stress mediators. N Engl J Med 338: 171-179.

Mestek A, Hurley JH, Bye LS, Campbell AD, Chen Y, Tian M et al (1995). The human mu opioid receptor: modulation of functional desensitization by calcium/calmodulin-dependent protein kinase and protein kinase C. J Neurosci 15: 2396-2406.

Miller GM, Bendor J, Tiefenbacher S, Yang H, Novak MA, Madras BK (2004). A mu-opioid receptor single nucleotide polymorphism in rhesus monkey: association with stress response and aggression. Mol Psychiatr 9: 99-108.

Modell S, Lauer CJ, Schreiber W, Huber J, Krieg JC, Holsboer F (1998). Hormonal response pattern in the combined DEX-CRH test is stable over time in subjects at high familial risk for affective disorders. Neuropsychopharmacology 18: 253-262.

Oslin DW, Berrettini W, Kranzler HR, Pettinati H, Gelernter J, Volpicelli JR et al (2003). A functional polymorphism of the muopioid receptor gene is associated with naltrexone response in alcohol-dependent patients. Neuropsychopharmacology 28: 1546-1552.

Peeters F, Nicholson NA, Berkhof J (2003). Cortisol responses to daily events in major depressive disorder. Psychosom Med 65: 836-841.

Ray LA, Hutchison KE (2004). A polymorphism of the mu-opioid receptor gene (OPRM1) and sensitivity to the effects of alcohol in humans. Alcohol Clin Exp Res 28: 1789-1795.

Richardson CG, Ratner PA (2005). A confirmatory factor analysis of the Fagerstrom Test for Nicotine Dependence. Addict Behav 30: 697-709.

Sander T, Gscheidel N, Wendel B, Samochowiec J, Smolka M, Rommelspacher $\mathrm{H}$ et al (1998). Human mu-opioid receptor variation and alcohol dependence. Alcohol Clin Exp Res 22: $2108-2110$. 
Sapolsky RM (2000). Glucocorticoids and hippocampal atrophy in neuropsychiatric disorders. Arch Gen Psychiatr 57: 925-935.

Schinka JA, Town T, Abdullah L, Crawford FC, Ordorica PI, Francis E et al (2002). A functional polymorphism within the mu-opioid receptor gene and risk for abuse of alcohol and other substances. Mol Psychiatry 7: 224-228.

Shi J, Hui L, Xu Y, Wang F, Huang W, Hu G (2002). Sequence variations in the mu-opioid receptor gene (OPRM1) associated with human addiction to heroin. Hum Mutat 19: 459-460.

Steptoe A, Kunz-Ebrecht S, Owen N, Feldman PJ, Willemsen G, Kirschbaum C et al (2003). Socioeconomic status and stressrelated biological responses over the working day. Psychosom Med 65: 461-470.

Szeto CY, Tang NL, Lee DT, Stadlin A (2001). Association between mu opioid receptor gene polymorphisms and Chinese heroin addicts. Neuroreport 12: 1103-1106.

Tan EC, Tan CH, Karupathivan U, Yap EP (2003). Mu opioid receptor gene polymorphisms and heroin dependence in Asian populations. Neuroreport 14: 569-572.

Town T, Abdullah L, Crawford F, Schinka J, Ordorica PI, Francis E et al (1999). Association of a functional mu-opioid receptor allele (+118A) with alcohol dependency. Am J Med Genet 88: 458-461.
Tsigos C, Chrousos GP (2002). Hypothalamic-pituitary-adrenal axis, neuroendocrine factors and stress. J Psychosom Res 53: 865-871.

Uhart M, McCaul ME, Oswald LM, Choi L, Wand GS (2004). GABRA6 gene polymorphism and an attenuated stress response. Mol Psychiatr 9: 998-1006.

Vaccarino AL, Kastin AJ (2000). Endogenous opiates: 1999. Peptides 21: 1975-2034.

Van Ree JM, Niesink RJ, Van WL, Ramsey NF, Kornet MM, Van Furth WR et al (2000). Endogenous opioids and reward. Eur J Pharmacol 405: 89-101.

Wand GS, McCaul M, Yang X, Reynolds J, Gotjen D, Lee S et al (2002). The mu-opioid receptor gene polymorphism (A118G) alters HPA axis activation induced by opioid receptor blockade. Neuropsychopharmacology 26: 106-114.

Wand GS, McCaul ME, Gotjen D, Reynolds J, Lee S (2001). Confirmation that offspring from families with alcohol-dependent individuals have greater hypothalamic-pituitary-adrenal axis activation induced by naloxone compared with offspring without a family history of alcohol dependence. Alcohol Clin Exp Res 25: 1134-1139.

Zeger SL, Liang KY (1986). Longitudinal data analysis for discrete and continuous outcomes. Biometrics 42: 121-130. 